\title{
Review
}

\section{An evaluation of the status of living collections for plant, environmental, and microbial research}

\author{
Kevin McCluskey $^{1, *}$ (i), Jill P Parsons ${ }^{2}$, Kimberly Quach $^{2}$ and Clifford S Duke ${ }^{2}$ \\ ${ }^{1}$ Fungal Genetics Stock Center, Department of Plant Pathology, Kansas State University, Manhattan, KS, USA \\ ${ }^{2}$ Office of Science Programs, Ecological Society of America, Washington, DC, USA \\ *Corresponding author (Email, mccluskeyk@ksu.edu)
}

\begin{abstract}
While living collections are critical for biological research, support for these foundational infrastructure elements is inconsistent, which makes quality control, regulatory compliance, and reproducibility difficult. In recent years, the Ecological Society of America has hosted several National Science Foundation-sponsored workshops to explore and enhance the sustainability of biological research infrastructure. At the same time, the United States Culture Collection Network has brought together managers of living collections to foster collaboration and information exchange within a specific living collections community. To assess the sustainability of collections, a survey was distributed to collection scientists whose responses provide a benchmark for evaluating the resiliency of these collections. Among the key observations were that plant collections have larger staffing requirements and that living microbe collections were the most vulnerable to retirements or other disruptions. Many higher plant and vertebrate collections have institutional support and several have endowments. Other collections depend on competitive grant support in an era of intense competition for these resources. Opportunities for synergy among living collections depend upon complementing the natural strong engagement with the research communities that depend on these collections with enhanced information sharing, communication, and collective action to keep them sustainable for the future. External efforts by funding agencies and publishers could reinforce the advantages of having professional management of research resources across every discipline.
\end{abstract}

[McCluskey Kevin, Parsons Jill P, Quach Kimberly, Duke Clifford S 2017 An evaluation of the status of living collections for plant, environmental, and microbial research. J. Biosci. 42 321-331]

\section{Introduction}

Living research resources make great impact, often far beyond their original intent (Furman and Stern 2011). These resources, often tied to a specific research community (Roche et al. 2014; Baddar et al. 2015), geographic region, or taxonomic domain (Boundy-Mills 2012; Namoff et al. 2010; Yoder 2013), can have a relatively predictable life history. Many begin as private collections developed by one researcher or consortium, as demonstration collections, wildlife or botanical preserves, or commercial or government biodiversity resources (Overmann 2015; Verkley et al. 2015). The trajectory of collections can be linked to the success of the larger community which utilizes the resources held by the collection. Some collections can become national or international biological resource centers, with either direct or grant-based government support. Other collections, especially botanic gardens, benefit from the input of a host institution and can have significant public support. Finally, collections can become orphaned by retirement or by changes in funding

Keywords. Biodiversity; genetics; interdisciplinary science; microbiology; natural resources

Supplementary materials pertaining to this article are available on the Journal of Biosciences Website. 
priorities. Once destroyed or otherwise lost, such collections may never be recreated.

Unlike biodiversity collections, medically relevant collections, tissue banks, databases, and living research resource repositories for bio-medical research have exclusive pathways for support. Medically relevant collections can receive support from the US National Institutes of Health and this support is typically administered by institutes such as the National Institute of Allergy and Infectious Disease (NIAID 2015) as well as through cancer and other diseasespecific specimen or tissue repository programs such as the National Cancer Institute Cooperative Human Tissue Network. Similarly, human health related databases such as the NCI Biospecimen Research Database (Moore 2014; Vaught 2016) receive support from the NIH budget. By way of contrast, some living vertebrate resources are independent, such as the mouse collection at the Jackson Laboratory (www.jax.org), while others, such as the research chimpanzee program (Kaiser 2015), are transitioning to more tractable models in recognition of the ethical issues posed by research with primates. Intramural resource repositories within the NIH include diverse organisms such as Zebrafish, Schistosomiasis, and even larger organisms such as swine or other animal models of infectious diseases. Many living medically relevant tissue and organism repositories interact through the International Society for Biological and Environmental Repositories (www.isber.org).

Some plant resources have support from the US Department of Agriculture as important sources for maintaining biodiversity for crop improvement, disease management, and to support expanded understanding of plant biological and molecular processes. With research and repository activities in 30 US states, the USDA National Program 301: Plant Genetic Resources, Genomics and Genetic Improvement (NP301) is a national and international leader in plant conservation and characterization. Among the activities tied to NP301 are 26 plant germplasm centers at locations around the country as well as a central back-up at the USDA National Laboratory for Genetic Resources Preservation in Ft. Collins, Colorado. These resources are accessible via the Genetic Resources Information Network (GRIN) or directly via interaction with curators. Other plant collections support public botanic gardens or have a large public component including as a tourist destination. Botanic gardens interact through the American Public Gardens Association or the Botanic Gardens Conservation International.

The USDA Agricultural Research Service (ARS) also maintains a collection of microbial resources at the Northern Regional Research Laboratory (NRRL) repository in Peoria, Illinois which also serves as a patent repository for microbial resources under the Budapest treaty, also known as an International Depository Authority (IDA). While most countries have only one IDA, the US has three IDAs including the USDA, the American Type Culture Collection (ATCC), and the National Center for Marine Algae and Microbiota. Other USDA supported microbial resource collections include an insect-pathogenic fungi collection (ARS Entomopathogenic Fungal Culture Collection), a Rhizobium collection, and the US National Fungus Collections, which is a mycological herbarium, albeit with links to GenBank and sometimes to living representatives as pure cultures at other collections or as commercial soil amendments.

For many years, the US National Science Foundation has supported a system of living research collections, representing diverse organisms and research systems. This program, originally called Living Stock Collections in Support of Biological Research (LSCBR), included research tools such as Drosophila, Peromyscus, Lemur, Arabidopsis, filamentous fungi, E. coli, Bacillus, and Chlamydomonas, as well as broader collections such as the ATCC, algal biodiversity collections, and mycorrhizal fungi. While ATCC has not received direct support from the NSF through the collection programs for many years, several collections which are deeply connected with their research community still rely on NSF support for salaries (table 1). In 2011 the LSCBR program was merged with Improvements to Biological Research Collections to form Collections in Support of Biological Research (CSBR), and curators of living collections were reminded that they were expected to work towards becoming self-sustaining. This was the first time living and non-living collections were placed in the same program. Since then there have been several changes to the program that supports living collections with the annual CSBR program (nsf11558) being replaced with a program on a biennial cycle with a 3 year limit in 2013 (nsf13557). In 2014 a revision returned the program to an annual submission cycle, still with the 3 year limit and with announced submission deadlines in September 2015 and August 2017. This program has two main tracks including either natural history collections or living stock collections, and a third track for changes to collection ownership. Emphasizing project based proposals rather than long-term sustenance, the recent changes to this program have allowed collections that were unable to obtain funds when the program provided long-term sustenance support to finally receive project support (table 1). This has unfortunately meant that some collections that have received support for as long as 50 years have needed to identify independent support, sometimes requiring relocation (McCluskey et al. 2016). In 2016 the NSF placed the collection program on hiatus (Nowogrodzki 2016b) and requested input on future directions. While the long-term status of this program remains uncertain, the NSF announced in May 2016 that proposals will be accepted at the 2017 deadline and that the program would resume a biennial cycle thereafter (Nowogrodzki 2016a). The announcement included the intent to evaluate the collection program in the context of the smaller infrastructure programs 
Table 1. Living collections receiving support from the US National Science Foundation*

\begin{tabular}{|c|c|c|c|c|c|}
\hline Collection name & $\begin{array}{l}\text { Organism } \\
\text { emphasis }\end{array}$ & Host institution & $\begin{array}{l}\text { Most recent NSF } \\
\text { Programs }\end{array}$ & $\begin{array}{l}\text { First } \\
\text { funding }\end{array}$ & $\begin{array}{l}\text { Last } \\
\text { funding }\end{array}$ \\
\hline American Type Culture Collection & $\begin{array}{l}\text { Biodiversity/ type } \\
\text { cultures }\end{array}$ & ATCC & LSCBR & 1963 & 2009 \\
\hline $\begin{array}{l}\text { Provasoli-Guillard Center for Culture } \\
\text { of Marine Phytoplankton, (Now the } \\
\text { National Center for Marine Algae and } \\
\text { Microbiota) }\end{array}$ & Algae & $\begin{array}{l}\text { Bigelow Laboratory for } \\
\text { Ocean Sciences }\end{array}$ & LSCBR/CSBR & 1972 & 2018 \\
\hline UTEX Culture Collecton of Algae & Algae & University of Texas & LSCBR/CSBR & 1952 & 2018 \\
\hline Drosophila Species Collection & Invertebrates & $\begin{array}{l}\text { Bowling Green State } \\
\text { University }\end{array}$ & LSCBR & 1974 & 1998 \\
\hline Drosophila Species Collection & Invertebrates & University of Arizona & LSCBR & 1974 & 2015 \\
\hline Drosophila Species Collection & Invertebrates & $\begin{array}{l}\text { University of California-San } \\
\text { Diego }\end{array}$ & CSBR & 1974 & 2018 \\
\hline Drosophila Stock Center & $\begin{array}{c}\text { Mutant } \\
\text { invertebrates }\end{array}$ & Indiana University & LSCBR & 1989 & 2014 \\
\hline The Chlamydomonas Genetics Center & Algae & Duke University & LSCBR & 1994 & 2004 \\
\hline The Chlamydomonas Resource Center & Algae & $\begin{array}{l}\text { University of Minnesota- } \\
\text { Twin Cities }\end{array}$ & CSBR & 1994 & 2019 \\
\hline Arabidopsis Biological Resource Center & Plants & Ohio State University & LSCBR/CSBR & 1991 & 2019 \\
\hline Bacillus Stock Center & Bacteria & Ohio State University & LSCBR/CSBR & 1978 & 2017 \\
\hline Fungal Genetics Stock Center & Filamentous fungi & Dartmouth College & NSF & 1961 & 1971 \\
\hline Fungal Genetics Stock Center & Filamentous fungi & Humboldt State University & МCB & 1971 & 1985 \\
\hline Fungal Genetics Stock Center & Filamentous fungi & $\begin{array}{l}\text { University of Kansas Medical } \\
\text { Center }\end{array}$ & LSCBR & 1985 & 2004 \\
\hline Fungal Genetics Stock Center & Filamentous fungi & $\begin{array}{l}\text { University of Missouri- } \\
\text { Kansas City }\end{array}$ & LSCBR/CSBR & 1960 & 2015 \\
\hline $\begin{array}{l}\text { International Culture Collection of VA } \\
\text { Mycorrhizal Fungi }\end{array}$ & Fungi & University of Florida & LSCBR & 1987 & 1989 \\
\hline $\begin{array}{l}\text { International Culture Collection of VA } \\
\text { Mycorrhizal Fungi }\end{array}$ & Fungi & West Virginia University & LSCBR/CSBR & 1990 & 2017 \\
\hline $\begin{array}{l}\text { Escherichia coli K-12 Genetic Stock } \\
\text { Culture Collection }\end{array}$ & Bacteria & Yale University & LSCBR/CSBR & 1966 & 2018 \\
\hline Peromyscus Stock Center & Vertebrate & $\begin{array}{l}\text { University of South Carolina } \\
\text { at Columbia }\end{array}$ & CSBR & 2000 & 2017 \\
\hline Phaff Yeast Culture Collection & Yeast & $\begin{array}{l}\text { University of California, } \\
\text { Davis }\end{array}$ & CSBR & 2014 & 2017 \\
\hline Montgomery Botanical Center & Plants & $\begin{array}{l}\text { Montgomery Botanical } \\
\text { Center }\end{array}$ & CSBR & 2012 & 2017 \\
\hline Duke Lemur Cent & Verte & Duke University & CSBR & 1996 & 2018 \\
\hline Genetic Stocks of the Axolotl & Vertebrate & Indiana University & MCB & 1972 & 2004 \\
\hline
\end{tabular}

* Data from NSF award database, 5/31/2016. Collections listed multiple times received support from programs outside the Division of Biological Infrastructure.

with 'the goal of informing the FY18 [fiscal year 2018] budget request' and that CSBR would be evaluated in the context of the postdoctoral fellowship program (nsf15501) that has a track emphasizing collections and the Advanced Digitization of Biodiversity Collections programs (ADBC, nsf15576). It should be noted that many significant living collections that received or currently receive support do not have a biodiversity emphasis and as such are not well aligned with the ADBC program mission.

Historically, culture collections interact through the World Federation for Culture Collections which is a Multidisciplinary Commission of the International Union of Biological Sciences (IUBS) and also a Federation within the International
Union of Microbiological Societies (IUMS). Because many living collections have genetic emphases, they are unlike biodiversity collections in the broadest sense. For example, significant numbers of strains in the Fungal Genetics Stock Center collection share a single progenitor and the Coli Genetic Stock Center exclusively holds K12 derivatives. In the USA, living microbe collections interacted through the US Federation for Culture Collections although this entity ceased activities in the late 1990's and last published a newsletter in 2002 (www.usfcc.us). Filling this gap, the US Culture Collection Network is the main activity of an NSF Research Coordination Network grant for a community of ex situ microbial germplasm repositories (NSF DBI 1534564). 
Distinct collection types often depend on external resources for data integration. For biodiversity resources, the Global Biodiversity Information Facility (GBIF, www.gbif. org), or the US Geological Survey BISON (http://bison. usgs.ornl.gov) project provide data resources and aggregation. For microbial resources, including research repositories and biodiversity or type strain collections, resources such as the information aggregator StrainInfo.net and the World Data Centre for Micro-organisms (www.wdcm.org) provide data portals. Similarly, collections can provide links and data to public resources such as the US National Library of Medicine (PubMed). These data can include links from genome programs and publications through the link-out feature and can associate mutant microorganism strains with the deficient gene through the gene search resource (http:// www.ncbi.nlm.nih.gov/gene/).

For the past six years, the Ecological Society of America (ESA) has led several workshops and projects to raise awareness of the importance of biological infrastructure to scientific discovery and to advance the sustainability discussion in the biological infrastructure community. Two workshops, held in 2010 and 2012, were sponsored by the NSF. The first workshop on strategies for financial sustainability of biological research infrastructure, brought together managers of biological research infrastructure projects including databases, field stations, and living collections. The workshop identified the challenges to keeping long-term biological infrastructure projects operational, investigated different sustainability models, and developed recommendations for future collaboration. The second workshop brought together managers of living stocks collections, policy professionals, and agency representatives to craft strategies for developing and innovating living collections in the US. Both workshops identified a number of opportunities and challenges to sustaining biological infrastructure. They ultimately led to the creation of ESA's Sustaining Biological Infrastructure (SBI) Training Initiative (http://esa.org/sbi) which aims to create a future where vital biological infrastructure is innovative, sustained, and supports scientific discovery. SBI does this by conducting training courses to help scientists gain the business planning, marketing, and communication skills necessary to innovate and sustain research infrastructure. To learn more about these and related issues, a survey of 43 questions was sent to potential participants using mailing lists of the US Culture Collection Network and the Ecolog-L listserv, hosted at the University of Maryland. The survey was entitled 'Strategies for Developing and Innovating Living Stocks Collections,' based on the 2012 workshop of the same title hosted by ESA and sponsored by NSF (Parsons and Duke 2013). Most questions included the option to provide freetext input. The questions are provided as online supplemental information.

\section{Discussion}

As with most surveys, response rates are a challenge. The present survey garnered sixty-two valid responses. With the exception of four responses made by different individuals from one living algae collection, all responses were from unique computer domains (IP Addresses). Among the respondents who answered the question 'What types of organisms are housed in your collection?' the most common response was 'plants' and six additional responses selected 'other' and wrote in 'algae'. The second most common responses were prokaryotes and fungi with vertebrates and arthropods being also represented. Nearly half of all responses (29) were from plant collection curators with 18 prokaryote and 15 fungal collections also responding. One response indicated that birds were the focus of the collection. Additionally, all of the respondents indicated whether their collection focused on wild-type or genetically modified materials. Thirty-nine, or $62 \%$, have collections of wild-type organisms. Eight collections hold genetically modified materials and fifteen responses provided text input after selecting 'other'. Among these, cultivated plants were mentioned. One said that they held a variety of mutants generated by classical as well as molecular mutation, and thirteen said that they held cultivars improved by breeding and selection and also wild-collected material. One collection indicated that data were maintained in addition to other resources, although all collections typically maintain various data in support of the physical resources.

The scale of collections varied greatly with a small majority having more than 5,000 accessions (table 2). Most collections were established between 1950 and 1990 (figure 1) although some were established much earlier. One indicated it was established during the administration of President Lincoln, while another indicated it was originally established in the 'late 1800s'.

While every collection has its own origins and is engaged with its own research community, continuous growth is a characteristic of all collections, some by deposit from individual researchers, others by large coordinated deposit, and some by accretion where materials from other collections are accepted to prevent loss associated with retirements. When asked how materials were identified for accession, with multiple responses allowed, nearly two thirds (65\%) said that they actively solicited deposit from colleagues. Similarly, 58\% said that colleagues contacted them to deposit novel materials without having been solicited. This encouraging practice emphasizes how living collections can help support the resource sharing requirement from most granting agencies. Many collections (55\%) actively collect material in nature. This is an area where there is significant regulatory oversight and collections can simplify the process of resource utilization when the materials are already present in 
Table 2. Scale of collections

\begin{tabular}{lcc}
\hline $\begin{array}{c}\text { Number of } \\
\text { specimens }\end{array}$ & $\begin{array}{c}\text { Number of } \\
\text { collections }\end{array}$ & $\begin{array}{c}\text { Percentage of } \\
\text { responses }\end{array}$ \\
\hline $1-99$ & 1 & $1.6 \%$ \\
$100-499$ & 3 & $4.9 \%$ \\
$500-999$ & 5 & $8.2 \%$ \\
$1000-5000$ & 21 & $34.4 \%$ \\
Over 5000 & 31 & $50.8 \%$ \\
\hline
\end{tabular}

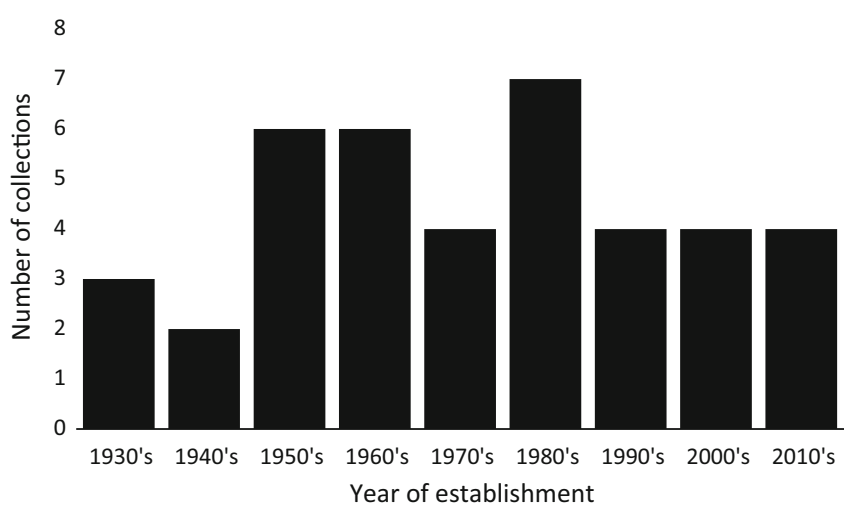

Figure 1. Year of collection establishment.

national collections with appropriate permits already established. Some collections generate materials in their own laboratory, but this was a minority. Eighteen collections made specific comments and among these were several that stated that they purchased their accessions from commercial sources. One stated that their responsibility was for the plantings in a built environment while another stated that they inherited their collection intact. One emphasized that the founders were wild-caught, but that they had an active breeding program and so most living members were born in captivity. One collection engages with crop germplasm committees to identify resources for acquisition.

While a small minority of collections were regional or local, the vast majority were national or international (52). Because many collections are closely associated with the research community that utilizes the materials, it was not unanticipated that more than three fourths of responses indicated that their collection held material that was not available from any other source. Because redundancy is one way to assure that key strains, varieties, or species remain available, the fact that most collections have unique materials emphasizes the importance of off-site back-up.

Another insight provided by this survey is the fact that while a majority of collections are staffed by a small number of dedicated workers (fewer than 9) and many collections (29) had four or fewer workers, more than one quarter have

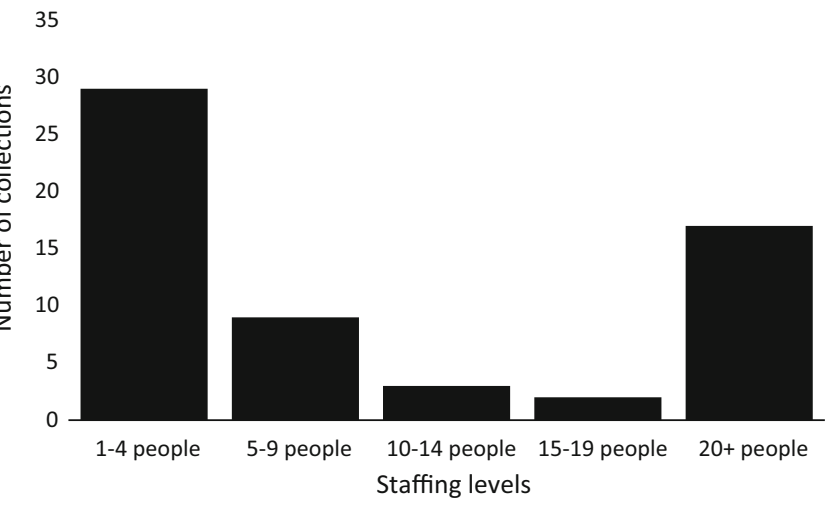

Figure 2. Staffing levels of different collections.

more than twenty workers. Interestingly, fifteen of the seventeen collections with twenty or more workers were plant collections and two were vertebrate collections (figure 2). This may be a function of the ability to preserve microbes in suspended animation for many years, either by cryopreservation, or desiccation.

Responses to the question of who uses the collection were free text and as such were complex. Fifty-eight responses were provided and the top two answers were researchers (42) and students (21). Other categories of collection users included educators (mentioned 11 times), the general public (10), as reference material (8), and to be used in environmental restoration, taxonomy, or for outreach. Nine responses specifically mentioned that they provide material for commercial research. This diverse user base has patterns seen in other responses to this survey. Most of the collections that mentioned restoration or public interest were plant collections. By way of contrast, collections that mentioned reference material were mostly microbial. Several collections specifically mentioned that they are engaged with genome programs. This emphasizes that if genome sequences are like books, living collections are the libraries.

Not surprisingly, most collections that responded to the survey communicate with their community via e-mail and disseminate information via a collection website, although only a few collections use social media. The third most commonly mentioned form of interaction was face-to-face interaction, and telephone interactions were fourth most common (mentioned by 39 collections or $67 \%$ of responses). User surveys are considered essential for best practices and for certification such as ISO 9001 (2008). Several collections have periodic newsletters, stakeholder meetings, or rely upon visits to the facility by stakeholders or by the general public. Public gardens or specialized vertebrate collections may have as many as 250,000 visitors annually.

Most of the collections that participated in the survey distribute or share material, although one said that they 
rarely give specimens to other facilities. Of the collections that distribute, only $23(39 \%)$ use websites as a point of sale for clients while more allowed direct contact via e-mail for requests and more than half allowed telephone requests.

Of 56 collections that responded to the question of how they shared materials, the majority (62\%) shared material through collaboration and smaller numbers considered the materials as gifts $(46 \%)$ or charged a fee for service/material provision (43\%). Three collections stated that they did not share materials, while eight stated that distribution was on a loan basis (suggesting that these materials are archival). Interestingly, fourteen collections $(25 \%)$ indicated that they provide images via the web. While sharing images can be very straightforward, distribution of living materials requires training and significant regulatory compliance. When asked about the most difficult thing about transporting living material, $44 \%$ ( 25 collections) stated that permitting was the most challenging obstacle. The expense of distribution was the second most common challenge, and nine collections listed viability as a limiting factor. Three collections stated that they did not ship living material. Among the text responses, import issues (permits), viability, and requirements for phytosanitary certificates were challenges. The education of customs agents is certainly an issue in this, as requests for phytosanitary certificates for microbe cultures have been received many times at the FGSC. Because phytosanitary certificates assert that a plant is free of contaminating microbes, this request presents an inherent contradiction and because most algal collections hold consortia, microbe-free specimens are impossible to obtain.

While permits may provide authority to transport or receive materials, intellectual property issues and international treaty obligations are significant factors limiting material exchange in a modern research environment. Of fifty four responses to a question about the use of a formal Material Transfer Agreement (MTA), twenty eight had an institution-specific MTA, two stated that they use the Universal Biological Material Transfer Agreement (Dedeurwaerdere 2006), and twenty four stated that they did not use an MTA at all. The modern requirement for MTAs can be a challenge for collections that were established before deposit MTAs were common (figure 1). Of the collections that use an MTA, more than half (54\%) do not allow re-distribution. Fewer (10 collections), specifically allow redistribution and several did not have a formal policy.
Financial support for collections is an important concern. Of 43 responses to a question of how collections allocate their funding, most collections (31) use more than $50 \%$ of their budget for staff salaries (table 3). Indeed, staff salaries are the major expense for most collections with maintenance, outreach, development, and fundraising being listed as $20 \%$ or less of their total budget by many respondents. Many collections indicated that they had no budget for outreach $(40 \%)$ or fundraising $(68 \%)$. Recapitulating the importance of financial stability, only one collection indicated that they were financially independent. Two indicated that they had recurring federal government support. Just over one quarter of responses (12) indicated that they had funding for only the next year or so. Eleven stated that they were secure for the next $1-3$ years and five stated that they had funds for 3-5 years. Ten collections (just over 21\%) had funding in place for 5-10 years. While some collections struggle to identify long-term sustainability (McCluskey et al. 2016), the global trend is toward increasing formalization of living collections through programs such as the MIRRI program in the EU (Schüngel et al. 2014), or through regional or national networks (http://www.wfcc.info/collections/networks/).

Because many collections are facing sustainability challenges, most collections (33, or $67 \%$ of responses) are addressing this by developing and increasing revenue streams or controlling costs. Other strategies to meeting collections' immediate and long-term sustainability challenges include creating continuity of staff, building good stakeholder relations and developing contingency and disaster recovery plans. The living collections community is clearly beginning to become more creative in their approach to financial sustainability. Some are making tough decisions to stay operational, such as 'setting priorities on collection items to be kept,' or working with local partners and stakeholders to reduce redundancies. Many are developing new products and services (McCluskey et al. 2016), diversifying their collections, and becoming more engaged with their stakeholders and users. As one respondent described, 'we provide services that generate revenue and are open to requests from stakeholders. We provide some expertise at no cost as an outreach effort.'

Many collections are looking to their users for funding, but only 24 (46\% of respondents) charge fees to access the materials in the collection (although 10 respondents skipped this question and eight of these were plant collections).

Table 3. Percentage of budget used for staff salaries

\begin{tabular}{|c|c|c|c|c|c|c|c|c|c|c|c|}
\hline Percentage budget for salaries & $0 \%$ & $10 \%$ & $20 \%$ & $30 \%$ & $40 \%$ & $50 \%$ & $60 \%$ & $70 \%$ & $80 \%$ & $90 \%$ & $100 \%$ \\
\hline Number of collections & 2 & 1 & 1 & 4 & 2 & 2 & 8 & 9 & 7 & 5 & 0 \\
\hline
\end{tabular}


Sixteen of the collections that do not charge fees were plant collections and seven were fungal collections.

Fees are, however, not arbitrary and many collections have a rubric to establish fees on time and resource utilization balanced with cost recovery requirements. Several collections have committee input into fee levels while others set their fees according to university requirements or market research based on competing or similar products. Most of the respondents indicate that they have charged fees for many years, often as a requirement by their sponsoring agency. Fees were described from two perspectives in user comments with several stating that as fees were raised, requests declined. Of the eighteen responses to this question, more than half (11) stated that fees were essential to their operation while others stated that fees were insignificant. One comment stated that they found it difficult to recover more than $25-30 \%$ of costs through fees.

Twenty-six responses to a question of why the collection does not charge fees emphasized that they had public support and could not charge fees, were part of a government agency and were prohibited from charging fees, or that they were obliged to provide materials freely as part of their mission. The practice of charging users is slowly becoming more commonplace among living collections, as demonstrated by the results of this survey, but it still seems unlikely that collections could become self-sustaining through user fees alone in the near future.

Because external factors can affect the sustainability of collections, the survey included a question about the impact of these factors. The most common response was that decreased federal funding has been a significant negative impact. This change is still being enacted and while several long-funded collections have lost their grant support, others are still supported. Most of the collections that rely on support from a host institution or organization, or receive a significant portion of their revenue from endowments, have faced funding challenges since the 2008 recession. Reduced government support, and the lack of stability in government funding, were major negative factors, while positive factors included the impact of microbial genomics adding value to materials in collections, a return to regional craft brewing (for yeast collections), and interest in the materials from emerging markets, such as biofuel production, biotechnology and the demand for native plants for ecosystem restoration. For some collections, shifts in public attitudes, such as increasingly valuing conservation and nature, are having a positive impact.

Because collections look to different metrics to define their success, we asked how collections measure their success. Most stated that the number of users was the most important measure of success while anecdotal testimonies from users was mentioned as important in guiding policy. The number of publications and citations were both listed as relatively important (23 and 21 collections respectively).

In free-text responses to this question only five listed the number of distributions as an important metric and one stated outright that they did not track impact. Interestingly, the use of a pseudo h-index where citations to use of material from collections are tracked rather than individual authors, gives a good metric for collection impact. By this metric, for example, the Fungal Genetics Stock Center has a pseudo-hindex of over 125, the Phaff Yeast Culture Collection has a pseudo-h-index of 63 and the UTEX algal collection has a pseudo-h-index of 140. Thirty-four follow-on responses indicate that metrics are used in annual evaluations, in grant proposals, and in reports to boards, provosts, and donors. Several of these responses also mentioned communicating these metrics on their websites, to the press, and via social media. Interestingly, one collection circulates these metrics internally to increase staff morale. The level of user interest in these metrics seems to vary by collection. As one respondent indicated, 'We really only report this information to [our funding agency] to keep that line of funding coming in. Most of our users/customers don't care about metrics as they do about availability of the cultures.' Forty-two respondents emphasized that sustainable funding for living collections was dependent on understanding the value of collections. It is, however, difficult to place a financial value on collection holdings because they can be the result of millions of dollars in research support to many scientists over decades.

Large numbers of collection scientists use the data they generate to advocate for collections by attending and/or giving papers at meetings. Many respondents use communication with the general public as a means of advocating for their collection and the collection community. A small number of respondents indicated that they did not spend time advocating for collections. One of them explained that '.. in the past I have written editorials and a couple of articles related to collections. So far as I can tell these have had minimal impact. Now I have to put my efforts into areas that promise some return.'

Perhaps as an indicator of the overall stability of the collection community, a majority of those who responded indicated that their collection would continue to maintain materials if they departed personally. The eight responses where the collection would not be maintained in their absence are more of a concern. All eight of these were microbial collections with one holding both fungi and prokaryotes, three holding only fungi, and four holding only prokaryotes.

One question invited input on factors which ensure the long-term existence of the collection. There were thirty-nine responses to this question, although not everyone understood the question similarly. Some interpreted this question as 
what funding was available and cited institutional support, federal budget mandate, or a successful business plan as being key to long-term survival of their resource. Others mentioned planning and dedicated curation as being key to the sustainability of their collection, while several mentioned engagement with their specific research community. Implementation of best practices for long-term storage, including cryopreservation, was mentioned as a mechanism for longterm viability. Only two collections responded negatively and these comments emphasized that collections without a formal mandate are among the most vulnerable.

Succession planning and risk management have been significant challenges to the sustainability of living collections (Parsons and Duke 2013) and continue to be today. Twentyfour respondents described their succession plan. They included the observation that trained curators were difficult to replace and that early identification of potential successors was highly worthwhile. Many stated that they had no succession plan and that the decision would be made by administrators with no clear investment in the collection. Development of Standard Operating Protocol guides, aggressive advocacy, and networking were all cited as being important for succession. Some respondents expressed confidence in the longevity of their collections simply because the research community was highly reliant upon it as a resource. Some collections are trying to ensure their longevity by storing specimens at a back-up facility or engaging in cryopreservation, but many appear to have no logistical back-up plans in the event of an emergency. The responses below describe just a few of the challenges that collection scientists encounter when trying to plan for the future:

'I've been on soft money my entire career. It's hard for me to imagine a young person with my skillset in today's funding climate being willing to take that risk.'

'One challenge at the moment is a succession plan for our curators. As they are approaching retirement the need to train new curators is paramount but the resources to do it are unavailable.'

'Managing to see the collection through to sunnier times allows one to feel the onus of a $5^{\text {th }}$ century Byzantine monk recopying books while barbarians rampage civil society.'

When asked to describe the most critical sustainability challenges for the living collections community, more than half (23) respondents cited the lack of consistent public and federal funding as the primary concern. Five (12\%) participants highlighted external factors, such as climate change, pollution, invasive species, biodiversity and habitat loss, and events such as drought or fire. Three (7\%) respondents said that prioritizing support for collections, or 'determining how many collections are justifiable based on hard evidence rather than sentiment' was of primary importance when considering the sustainability of the living collection community as a whole.

A potential bright spot was the acknowledgement that most collection workers are able to interact with other collection managers and many did so multiple times per year. These interactions were through formal networks, like the US Culture Collection Network or the American Public Gardens Association, or informally via phone or e-mail. These interactions were described as being important to discuss common problems and solutions, to maintain community cohesiveness, to increase understanding of shared issues, and to identify opportunities. The level of interaction and dialogue among the living collection community appears to have increased immensely in recent years; at the 2012 ESA workshop on developing and innovating living stocks collections, most of the collections represented had little or no contact with other collection staff. This could be due to the challenges collections face as a community and/or the expansion of formal and informal opportunities for collection managers and directors to engage with each other. Whatever the cause, increased communication and collective action as a community may be a key driving force in the future sustainability of living collections.

Thirty-nine of forty five respondents stated that they were interested in further formal engagement and acknowledged the US NSF Research Coordination Network (RCN) as a desirable format for this interaction. Some of the suggested goals for a future $\mathrm{RCN}$ of the living collections community include:

- Increasing communication and collaboration among collection managers

- Furthering communication between collection managers and funding agencies

- Collectively advocating for support and increasing the profile of living collections, while serving as a unified voice on the importance of living collections for scientific discovery

- Enhancing data management across collections,

- Building capacity among collection managers

- Identifying common challenges and potential solutions for long-term sustainability

One respondent emphasized that living collections 'need to be thought of as more than warehouses for biological materials.'

\section{Conclusions}

Among the key findings of the present survey were that collections of living plants and animals had larger staff requirements than collections of microbes, that collections of 
living microbes were more likely to be vulnerable in the long-term than collections holding plants or animals, and that relocation when faced with changes in support or institutional commitment is disruptive to staff and to the research communities served by living collections. Collections of plants were comprised of three major groups including USDA crop germplasm repositories, biodiversity collections, and botanic gardens. Among these, only the USDA crop germplasm system is well supported, has implemented best practices and has the stability to train and maintain expert staff. Collections of vertebrate animals typically held fewer individuals and, other than USDA livestock collections, emphasized species diversity rather than genetic diversity within a species. Microbial collections were either supported by the USDA on a continuing basis, by periodic grants from the US NSF, or through institutional support and fees. A special type of microbe collection, called an International Depository Authority exists to preserve microbes described in patents, and they charge very high fees for accession and maintenance. Collections of vertebrate and invertebrate animals have unique challenges. Public biodiversity or genetic invertebrate collections are most similar in scope and support to microbe collections while collections of vertebrate or invertebrate animals that have relevance to human health, or which include models of human disease, have access to funding mechanisms not available to biodiversity collections.

Living collections engage diverse communities including research communities, agricultural crop, human and livestock disease communities, biodiversity and ecological restoration communities, and through gardens and visitor programs, the general public. Plant collections that emphasize ecological restoration are more likely to be regional in scope while public botanic collections often include representatives from diverse biomes.

Many living collections face similar challenges. For example, both microbe and plant collections face regulation by the USDA Animal and Plant Health Inspection Service (APHIS), and plant or animal collections must also conform to regulations by the US Fish and Wildlife service. All collections that provide or exchange material with clients must comply with International Air Transport Association shipping regulations.

New international treaty obligations, either through the Convention on Biological Diversity, and especially with regard to its Nagoya Protocol on Access and Benefit Sharing, or the guidelines of the UN Food and Agriculture Commission on Genetic Resources for Food and Agriculture impact the ability to exchange and utilize genetic resources for commercial applications. Prior informed consent is the standard by which genetic resources can be utilized, and this pertains equally to international obligations and to local regulations. No longer can resources be taken from public or private lands without benefit sharing, a situation called a microbial 'commons' (Uhlir 2011).

Among the similarities between living microbe and botanic gardens is the fact that there is no formal accrediting organization for either. The Organization for Economic Cooperation and Development has published best practice guidelines for microbial collections and these are similar in scope and tone to the best practice guidelines published by ISBER (Campbell et al. 2012). Some collections seek external certifications, such as ISO 9001, although these do not directly deal with the issues of validity of materials in living collections. One standard does certify producers of reference material (Guide 2009) and several respondents to the present survey indicated that they did provide reference material.

Identifying and obtaining funding for living collections is a challenge without regard to the type of collection (Smith et al. 2014). Living microbe collections face the additional problem of dealing with peer-to-peer exchanges where accession numbers from public collections become associated with material of undefined or questionable provenance. This is similar to the challenges faced by exchange of mammalian cell lines (ASN-2010). A myriad of examples of the impact of shared resources demonstrate the value in terms of research reproducibility (Vasilevsky et al. 2013; Collins and Tabak 2014) and contributions to improving the human condition (Dugan et al. 2011; Furman and Stern 2011). The long-term nature of research repositories of every type underscores the fact that value may be separated from the immediate cost and emphasizes the benefit of maintaining such resources (Stern 2004).

An international survey of culture collection practices that focuses on microbial resources determined that there were diverse motivations toward outward sharing (Dedeurwaerdere et al. 2016). Among these was a strong sense of the ethics of stewardship of shared resources. The present survey shows that US living collection curators and managers have this same sense of dedication to their resources and that this is an important component in the potential for long-term survivability of these shared resources. Many of the responses to the present survey identified advocating for increased support for living collections as a key to the longterm viability of collections. These collections may not be economically self-sustainable but, based on demonstrated impact, they are foundational to diverse research enterprises including agriculture, health, biodiversity, and public appreciation of nature. While coordination between collections is already increasing in response to sustainability challenges, more formal opportunities to promote information sharing, communication, and collective action, such as Research Coordination Networks, may be critical to the ultimate longevity of many collections and to the research community as a whole. The present system of competitive 
funding and of requiring that the curators or managers of a resource be responsible for its long-term viability detracts from the effort to maintain and protect the physical materials. It creates a community of 'haves' and 'have nots' where medically relevant collections can anticipate high levels of support while collections that support individual research communities, ecosystems, or taxonomic divisions are left to compete among themselves for a dwindling slice of the research funding pie.

There are simple steps that can be implemented to secure the important biological research infrastructure represented by living collections. Sustenance funding should be available on a long-term basis with three year grants being reserved for projects to improve or upgrade collections. Funding agencies should mandate that living resources generated through grant support be deposited in public collections for unbiased, long-term, professional management. This is essential to ensure that the non-exclusive right to develop research results under the Bayh-Dole act (Feldman 2015) are maintained and intact when changes in technology or new insights mean that results have new or unrealized value. Publishers should require accession numbers from public research collections for key living resources prior to publication (Bandrowski et al. 2016), as was done for DNA sequences in the 1980s (Burks and Tomlinson 1989). Collections will have new obligations in this modern era. They will be required to insure regulatory compliance for all material offered for deposit, or requested by bona fide clients. They will need to develop shared data to insure that materials in the collection are available for use by the research community, as is being done for microbial collections (Wu et al. 2017). Collections will need to obtain external certification for their quality management plans and for the materials that they distribute to clients. Regulatory agencies will need to integrate with living collections to provide legal avenues for researchers to obtain the materials they need for their programs. As we transition to a new era of biological research, living collections, like the Carnegie libraries of the early 20th Century (Bobinski 1969), promote open access to shared research material and represent a new research commons for the good of all of mankind.

\section{Acknowledgements}

The research coordination network for a community of ex situ microbial germplasm repositories is supported by Grant DBI 1534564 from the US National Science Foundation. The survey, and JPP, KQ, and CSD, were supported by Grant DBI 1247285 from NSF. This is publication number 16-189-J of the Kansas Agricultural Experiment Station. The survey was approved by the Kansas State University Institutional Review
Board and was determined to be exempt from further IRB review according to 45 CFR 46.101, B:2:11.

\section{References}

ASN-ATCCSDOW 2010 Cell line misidentification: the beginning of the end. Nat. Rev. Cancer. 10 441-448

Baddar NWAH, Woodcock MR, Khatri S, Kump DK, Voss SR 2015 Sal-site: research resources for the Mexican Axolotl. Salamanders Regen. Res. Methods Protoc. 1290 321-336

Bandrowski A, Brush M, Grethe JS, Haendel MA, Kennedy DN, Hill S, Hof PR, Martone ME, Pols M and Tan SC 2016 The resource identification initiative: a cultural shift in publishing. $J$. Comp. Neurol. 524 8-22

Bobinski GS 1969 Carnegie libraries: their history and impact on American public library development. Amer Library Assn

Boundy-Mills K 2012 Yeast culture collections of the world: meeting the needs of industrial researchers. J. Ind. Microbiol. Biotechnol. 39 673-680

Burks C and Tomlinson LJ 1989 Submission of data to GenBank. Proc. Natl. Acad. Sci. 86 408-408

Campbell L, Betsou F, Garcia D, Giri J, Pitt K, Pugh R, Sexton K, Skubitz A, Somiari S and Astrin J 2012 Best practices for repositories - collection, storage, retrieval and distribution of biological materials for research. Biopreserv. Biobank. 10 79-161

Collins FS, Tabak LA 2014 NIH plans to enhance reproducibility. Nature 505612

Dedeurwaerdere T 2006 The institutional economics of sharing biological information. Int. Soc. Sci. J. 58 351-368

Dedeurwaerdere T, Melindi-Ghidi P and Broggiato A 2016 Global scientific research commons under the Nagoya Protocol: towards a collaborative economy model for the sharing of basic research assets. Environ. Sci. Policy $551-10$

Dugan FM Jr., Wiest A and McCluskey K 2011 Public germplasm collections and revolutions in biotechnology. J. Biosci. 36 205-209

Feldman AM 2015 The Bayh-Dole Act, A Lion without Claws. Clin. Transl. Sci. 8 3-4

Furman JL and Stern S 2011 Climbing atop the shoulders of giants: The impact of institutions on cumulative research. Am. Econ. Rev. 101 1933-1963

Guide I 2009 General requirements for the competence of reference material producers (ISO, Geneva)

Kaiser J 2015 An end to US chimp research. Science 3501013

McCluskey K, et al. 2016 The US Culture Collection Network Lays the Foundation for Progress in Preservation of Valuable Microbial Resources. Phytopathology 106 532-540

Moore HM 2014 Moving toward biospecimen harmonization with evidence-based practices. Biopreserv. Biobank. 1279

Namoff S, Husby CE, Francisco-Ortega J, Noblick LR, Lewis CE and Griffith MP 2010 How well does a botanical garden collection of a rare palm capture the genetic variation in a wild population? Biol. Conserv. 143 1110-1117

NIAID 2015 Microbiology and Infectious Diseases Biological Research Repository (MID-BRR) in Services DoHaH (ed.) National Institute of Allergy and Infectious Diseases 
Nowogrodzki A 2016a Biological specimen troves get a reprieve. Nat. News. doi:10.1038/nature.2016.19995

Nowogrodzki A 2016b Biological specimen troves threatened by funding pause. Nature $\mathbf{5 3 1} 561$

Overmann J 2015 Significance and future role of microbial resource centers. Syst. Appl. Microbiol. 38 258-265

Parsons JP and Duke CS 2013 Strategies for developing and innovating living stocks collections: an ESA workshop report. Bull. Ecol. Soc. Am. 94 118-129

Roche CM, Loros JJ, McCluskey K and Glass NL 2014 Neurospora crassa: Looking back and looking forward at a model microbe. Am. J. Bot. 101 2022-2035

Schüngel M, Smith D, Bizet C, Stackebrandt E and Consortium M 2014 The role of the European Microbial Resource Research Infrastructure Project. Enliven. Microbe Microbial. Tech. 1001

Smith D, McCluskey K and Stackebrandt E 2014 Investment into the future of microbial resources: culture collection funding models and BRC business plans for biological resource centres. Springerplus $\mathbf{3} 81$
Stern S 2004 Biological Resource Centers. Brookings Institution Press, Washington DC

Uhlir PF 2011 Designing the microbial research commons: Proceedings of an International Workshop. National Academies Press

Vasilevsky NA, Brush MH, Paddock H, Ponting L, Tripathy SJ, LaRocca GM and Haendel MA 2013 On the reproducibility of science: unique identification of research resources in the biomedical literature. PeerJ. 1 e148

Vaught J 2016 Biobanking comes of age: the transition to biospecimen science. Annu. Rev. Pharmacol. Toxicol. 56 211-228

Verkley GJ, Rossman A and Crouch JA 2015 The Role of Herbaria and Culture Collections. Systematics and Evolution (Springer)

$\mathrm{Wu} \mathrm{L}$, et al. 2017. World data centre for microorganisms: an information infrastructure to explore and utilize preserved microbial strains worldwide. Nucleic Acids Res. 45 D611-D618

Yoder AD 2013 The lemur revolution starts now: the genomic coming of age for a non-model organism. Mol. Phylogenet. Evol. 66 442-452

MS received 25 February 2017; accepted 23 March 2017

Corresponding editor: DuRgadAs P KASBEKAR 